\title{
Collapse Behaviour of a Concrete-Filled Steel Tubular Column Steel Beam Frame under Impact Loading
}

\author{
Lian Song, ${ }^{1,2}$ Hao Hu ${ }^{1},{ }^{1,3}$ Jian $\mathrm{He},{ }^{1} \mathrm{Xu}$ Chen, ${ }^{2}$ and $\mathrm{Xi} \mathrm{Tu}^{4}$ \\ ${ }^{1}$ School of Civil Engineering, Chongqing University of Arts and Sciences, Chongqing 402160, China \\ ${ }^{2}$ Infrastructure Department, Chongqing University of Arts and Sciences, Chongqing 402160, China \\ ${ }^{3}$ Institute of Civil Engineering Disaster Prevention and Reduction, Chongqing University of Arts and Sciences, Chongqing 402160, \\ China \\ ${ }^{4}$ School of Civil Engineering, Chongqing University, Chongqing 400045, China \\ Correspondence should be addressed to Hao Hu; hhxkfy@126.com
}

Received 29 October 2020; Revised 11 December 2020; Accepted 10 April 2021; Published 23 April 2021

Academic Editor: Robert Cerný

Copyright (c) 2021 Lian Song et al. This is an open access article distributed under the Creative Commons Attribution License, which permits unrestricted use, distribution, and reproduction in any medium, provided the original work is properly cited.

The progressive collapse of a concrete-filled steel tubular (CFST) frame structure is studied subjected to impact loading of vehicle by the finite-element software ABAQUS, in the direct simulation method (DS) and alternate path method (AP), respectively. Firstly, a total of 14 reference specimens including 8 hollow steel tubes and 6 CFST specimens were numerically simulated under transverse impact loading for verification of finite-element models, which were compared with the existing test results, confirming the overall similarity between them. Secondly, a finite-element analysis (FEA) model is established to predict the impact behaviour of a five-storey and three-span composite frame which was composed of CFST columns and steel beams under impact vehicle loading. The failure mode, internal force-time curve, displacement-time curve, and mechanical performance of the CFST frame were obtained through analyzing. Finally, it is concluded that the result by the DS method is closer to the actual condition and the collapse process of the structure under impact load can be relatively accurately described; however, the AP method is not.

\section{Introduction}

Concrete-filled steel tubular (CFST) structures are widely encountered in civil engineering structures, such as composite frames, whose columns are the concrete-filled steel tubular (CFST), while beams are steel. Such structures are commonly exposed to accidental impact loads during the service. In recent years, there have been some successive structural collapses because of natural disasters and terrorist attacks around the world [1-3]. However, the continuous collapses due to accidental impact loads except some normal loads have not been considered in existing design specifications for safety of structure design [4-9].

So far, a number of researchers have studied the continuous collapses of structures in some occasional cases [1011]. A new partial distributed damage method to capture loss of stability phenomena is described for steel moment frames by Gerasimidis [12]. Salloum [13] demonstrated the vulnerability of a typical medium-rise circular RC building against progressive collapse as a result of blast generated waves. Ding [14] studied the failure probability of steel frame structures against terrorist attack. Jiang [15] presented progressive collapse resistance of three-dimensional steel frames with reinforced concrete slabs exposed to localized fire. The influence of building height on the robustness of reinforced concrete frame buildings to resist progressive collapse is investigated by Shan [16]. Wang [17] studied the analysis of stainless steel composite beam-to-column joint submodels and moment-resisting frames with the column removed. Kong [18] presented the results of a large-scale test on a three-dimensional (3D) composite floor specimen under the scenario of removed internal column. In [19], the influence of different span length of precast beams was studied under different column removal scenarios. Zhou [20] conducted the progressive collapse performance on three half-scale moment substructures, including a 
conventional RC specimen and two PC specimens using dowel bars and corbel. These studies provide useful information on the progressive collapse of different structures or components for the specific types of disasters concentrated in the explosion and fire but produce little data about composite frames by impact loads. Considering the dynamic effect via the impact loads on structures, it is very significant to make valid conclusions and recommendations on reasonable structure design for strengthening the ability of buildings to resist progressive collapse and ensure structural stability in the short time.

This research studies the continuous collapse performance and analysis method of a typical composite frame with concrete-filled steel tubular (CFST) columns and steel beams by accidental impact load of vehicle through the finite-element software ABAQUS. In this paper, the results of the finite-element model for a single member under dynamic impacts are coincident with that of existing experiments. The performance of this collapsed composite frame by the direct simulation method (DS) is compared with that by the alternate path method (AP) [21] in terms of displacement of the failure column top node and axial force of the adjacent columns.

\section{Verification of the Finite-Element Model}

2.1. Introduction of the Impact Test. As the basis for the verification of the planar frame, the simplest and most important model is the confined axial column subjected to lateral impact. Firstly, based on the ABAQUS software platform, a series of numerical analysis models for the existing tests of steel and CFST columns under lateral impact load are established. The verification tests consisted of 6 concrete-filled steel tubes and 8 hollow steel tube concrete tests. Detailed information is summarized in Table 1, where the symbol $B$ is the nominal external depth, $D$ is the outer diameter of the steel tube, $t_{s}$ is the thickness of the steel tube, $L$ is the length of the specimen, $V$ is the lateral impact velocity, and $M$ is the quality of the drop hammer.

2.2. The Finite-Element Model. In the finite-element model, four parts were built: a steel column, core concrete column, drop hammer, and endplate. The 4-node finite film strain linear reduced integral shell element (S4R) given in the finite-element program ABAQUS was used in this study to model the steel pipe. The 8 -node 3D linear reduction integral entity unit (C3D8R) was used to model the concrete.

In order to improve the computational efficiency, the 4bus unit of three-dimensional rigid body (R3D4) was used to model drop hammer and endplate because the stiffness of the hammer is larger than that of the impact column and its deformation hardly occurs. In the constitutive relation of materials, steel adopted with the bilinear model, core concrete adopted with the concrete damage plasticity model, and both are separately considering strain rate effect. The grid divided in the impact area is very dense, while that in the other parts is relatively sparse. Two ends of the steel pipe column were connected with the rigid end plates by command of Tie. The reference point established in the end plate was exerted by both the boundary constraint and axial force. The contact between the concrete-filled steel tubular column and drop hammer was built by surface-to-surface contact (Explicit). In addition, tangential behavior is used to consider the cohesive force because of tangential bond stress on the surfaces of concrete and steel pipe [25]. At this time, the relative sliding of the interface is simulated by the Columbia Friction Model, and the value of friction coefficient is 0.6 .

2.3. Result Verification. The failure modes obtained from the finite-element analysis (FEA) and tests are compared in Figure 1. The tests are from references [22-24], respectively. It can be seen that the simulated failure modes and deformation of the specimens are in good agreement with the experimental results. Both lateral displacement and impact force are compared as shown in Figures 2 and 3, respectively. Good agreement between the FEA and test results is achieved, as presented in Figure 2. Both the overall trend and numerical value are close to that of tests in Figure 3. $\Delta, P$, and Tare the lateral displacement, impact force, and impact time, respectively. It can be concluded that the typical results obtained from finite-element analysis are verified by that observed in the experimental investigation. Based on the model of extension, analysis of mechanical properties of CFST frames under impact load is carried out in Section 3.

\section{FEA of Progressive Collapse for the Planar Composite Frame}

3.1. Multiscale Finite-Element Model. Frame steel structures are commonly used in public buildings, multistorey industrial factories, and some special-purpose buildings, such as theatres, shopping malls, stations, exhibition halls, parking lots, and light industry workshops. According to the relevant standard [9], a typical planer frame structure with concrete-filled steel tubular column steel beam for 5 floors and 3 spans is designed as shown in Figure 4, which meets the design of the normal use requirements. The joints of the planer frame are external ring-plate-type-included intermediate and exterior joints, whose strengthened ring width is $100 \mathrm{~mm}$ and thickness is $12 \mathrm{~mm}$, as shown in Figure 5. This paper conducts a comparative study taking into account the failure of the underlying middle column B. Also, the basic information of the model as follows:

Building general information: column spacing of 6 meters, 3.6 meters height, column feet, and foundation consolidation

Frame column: $\bigcirc-360 \times 6 \mathrm{~mm}$

Frame beams: I-300 $\quad$ (height $\times$ width $\times$ belly $\times$ wing)
( $50 \times 8 \times 12 \mathrm{~mm}$

Material information: steel tubes and steel beams using steel S355, the yield stress of steel $f_{y}$ is $355 \mathrm{MPa}$, the ultimate strength of steel $f_{\mathrm{u}}$ is $470 \mathrm{MPa}$, and the cube strength of concrete $f_{c u}$ is $50 \mathrm{MPa}$ 
TABLE 1: Detail information of the testing specimens.

\begin{tabular}{|c|c|c|c|c|c|c|}
\hline Specimen label & Boundary condition & $D(B) \times t_{s} \times L(\mathrm{~mm} \times \mathrm{mm} \times \mathrm{mm})$ & $V(\mathrm{~m} / \mathrm{s})$ & $M(\mathrm{~kg})$ & Preloading $(\mathrm{kN})$ & Reference \\
\hline${ }^{*} \mathrm{MSH}$ & Pinned-pinned & $\square 100 \times 2 \times 2500$ & 3.57 & 592 & 288 & {$[22]$} \\
\hline${ }^{*} \mathrm{Pd} 1$ & Fixed-sliding & $0100 \times 2 \times 1000$ & 7.006 & 25.45 & 0 & \multirow{5}{*}[23]{} \\
\hline${ }^{*} \mathrm{Pd} 2$ & Fixed-sliding & $\mathrm{O} 100 \times 2 \times 1000$ & 6.998 & 25.45 & 88 & \\
\hline${ }^{*} \mathrm{Pd} 3$ & Fixed-sliding & $\mathrm{O} 100 \times 2 \times 1000$ & 6.995 & 25.45 & 163 & \\
\hline${ }^{*} \mathrm{Pd} 4$ & Fixed-sliding & $0100 \times 2 \times 1000$ & 7.012 & 25.45 & 196 & \\
\hline${ }^{*} \operatorname{Pd} 6$ & Fixed-sliding & $0100 \times 2 \times 1000$ & 7.006 & 25.45 & 228 & \\
\hline${ }^{*} \mathrm{HCC}$ & Fixed-fixed & $0180 \times 3.65 \times 1940$ & 7.73 & 465 & 0 & \multirow{8}{*}[24]{} \\
\hline CC1 & Fixed-fixed & $0180 \times 3.65 \times 1940$ & 9.21 & 465 & 0 & \\
\hline CC2 & Fixed-fixed & $0180 \times 3.65 \times 1940$ & 6.4 & 920 & 0 & \\
\hline $\mathrm{CC} 3$ & Fixed-fixed & $0180 \times 3.65 \times 1940$ & 9.67 & 465 & 0 & \\
\hline${ }^{*} \mathrm{HSS}$ & Pinned-pinned & $0180 \times 3.65 \times 2800$ & 4.25 & 465 & 0 & \\
\hline SS1 & Pinned-pinned & $\mathrm{O} 180 \times 3.65 \times 2800$ & 8.05 & 465 & 0 & \\
\hline SS2 & Pinned-pinned & $\mathrm{O} 180 \times 3.65 \times 2800$ & 5.69 & 920 & 0 & \\
\hline SS3 & Pinned-pinned & $0180 \times 3.65 \times 2800$ & 8.93 & 465 & 0 & \\
\hline
\end{tabular}

The specimens with asterisk in label are hollow steel tubes.
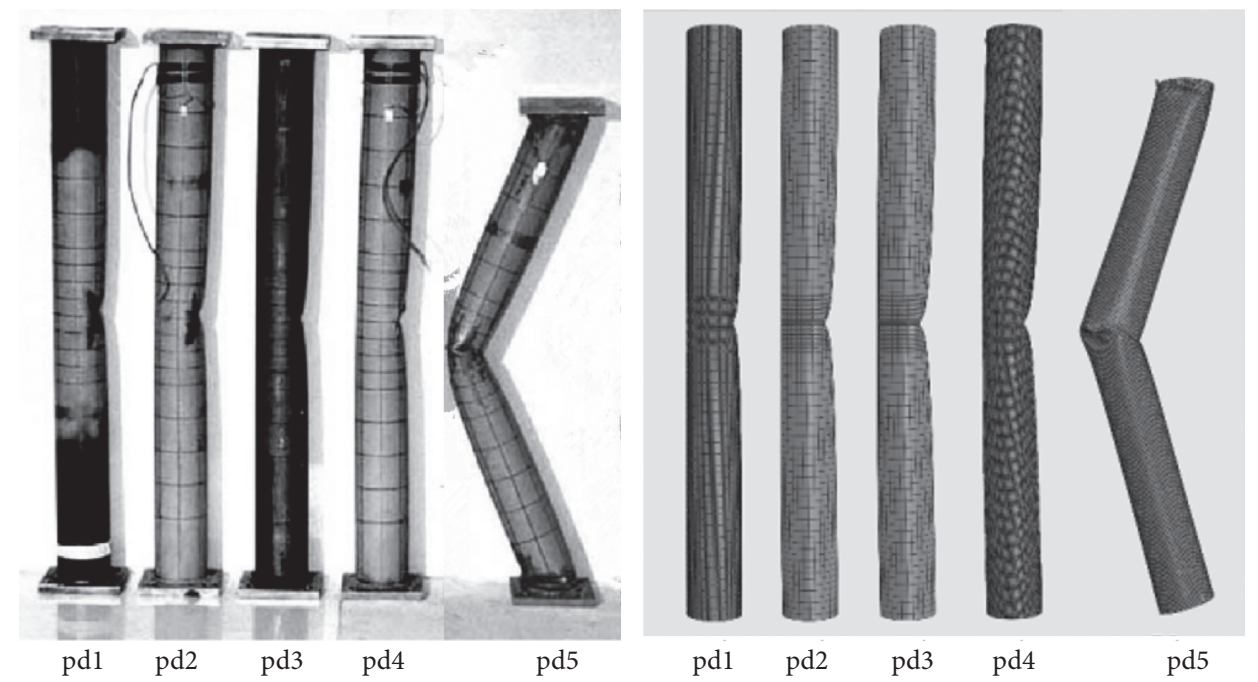

(a)
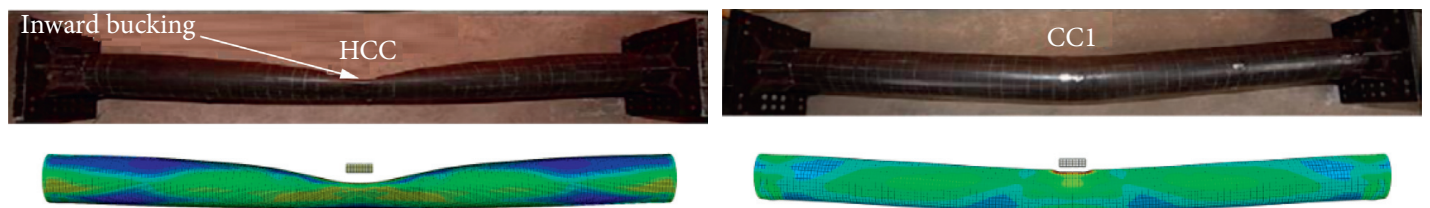

(b)
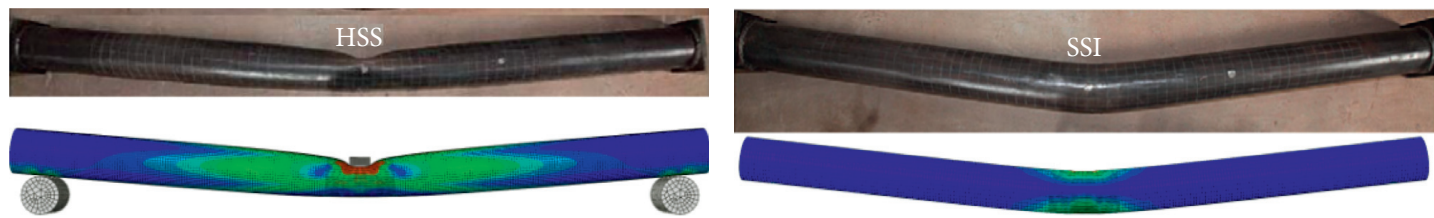

(c)

Figure 1: Failure mode comparison tests and FEA. (a) Failure tests from [22]. (b) Failure tests from reference [23]. (c) Failure tests from [24]. 


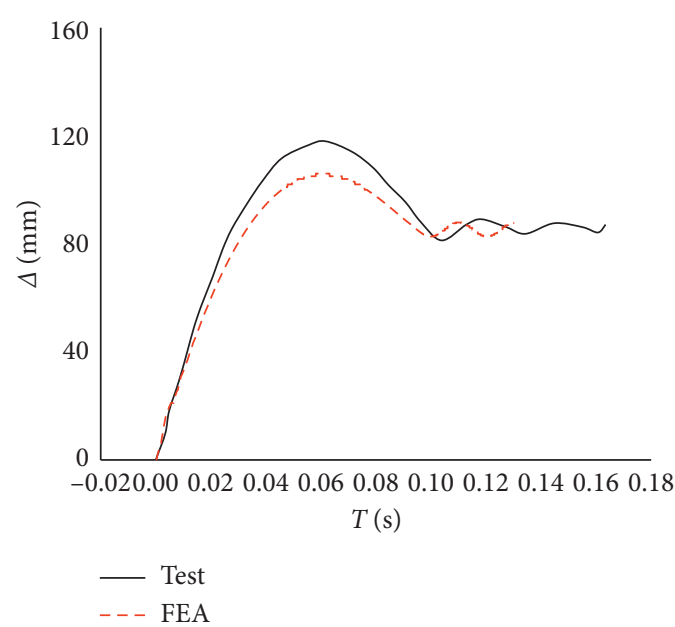

(a)

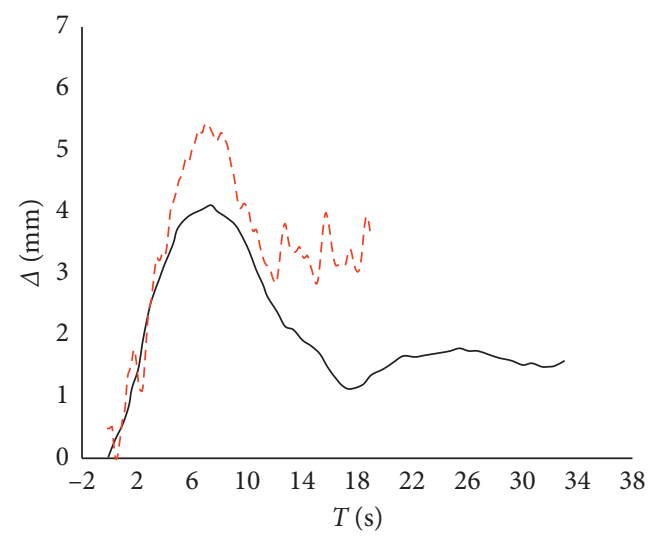

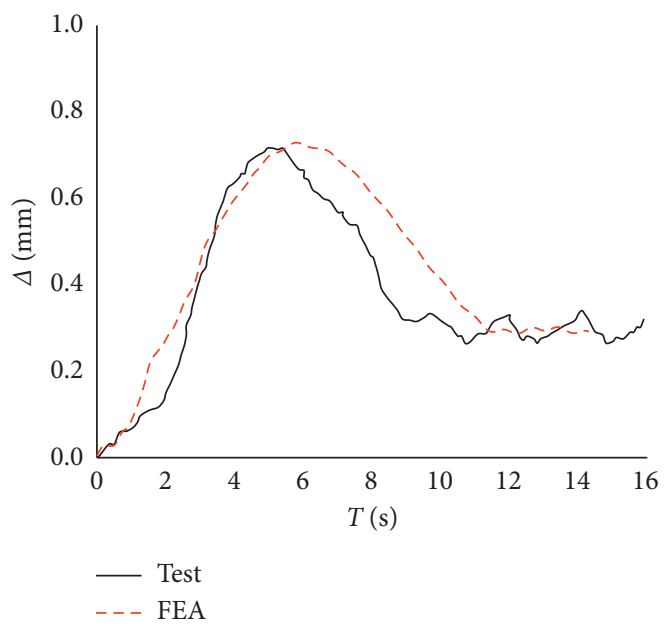

(b)

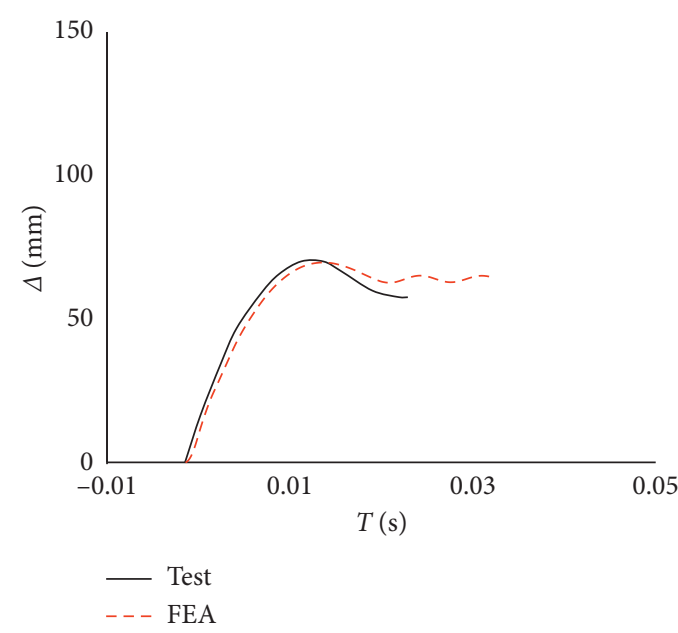

(d)

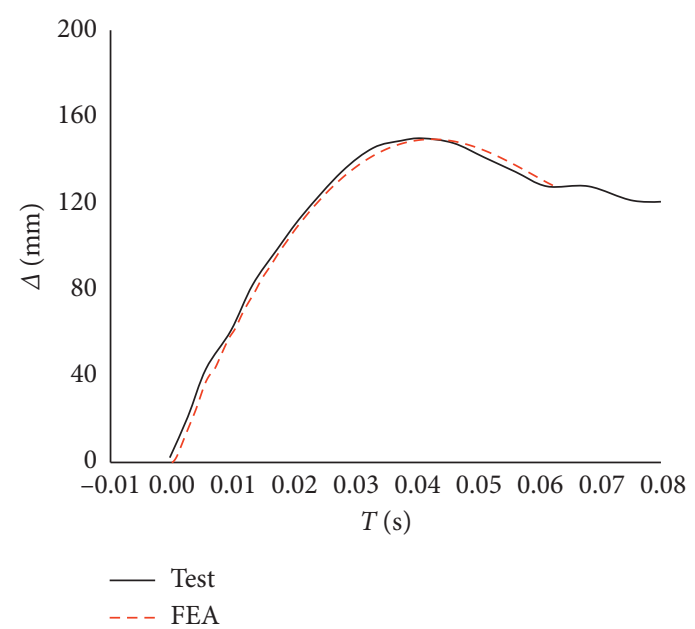

(f)

Figure 2: Continued. 


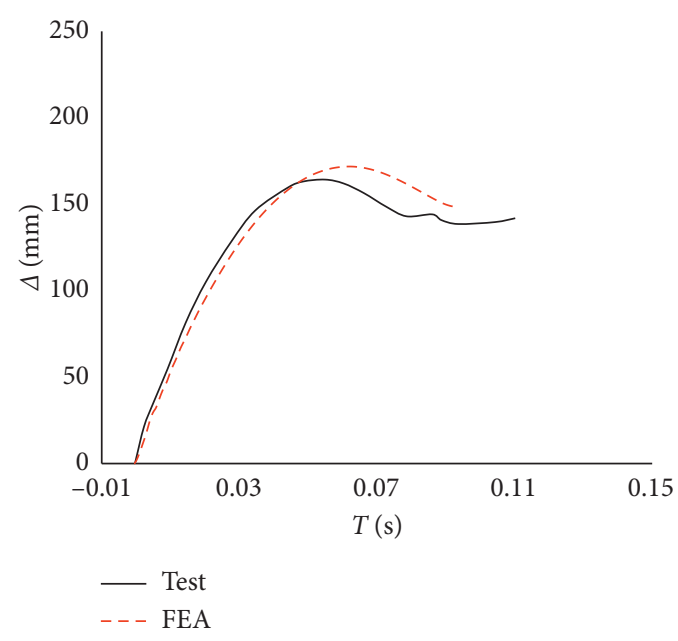

(g)

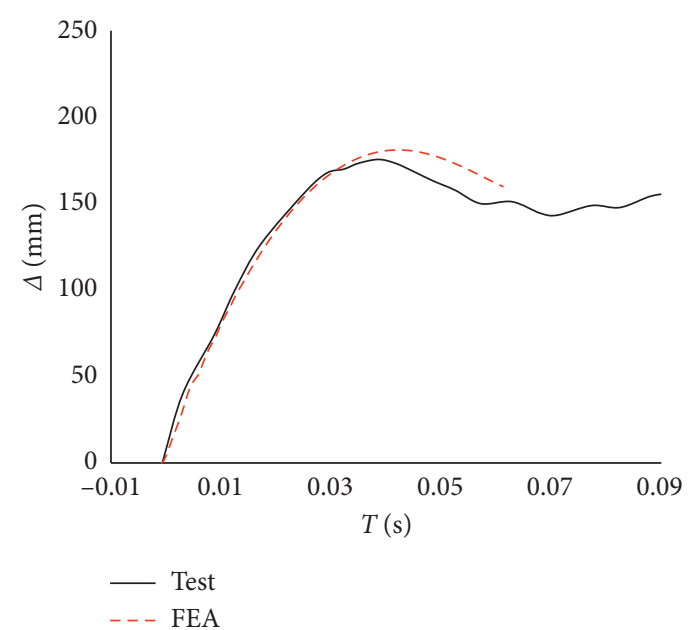

(h)

Figure 2: Lateral displacement $(\Delta$ ) versus time (T) curves. (a) MSH, (b) Pd1, (c) Pd2, (d) CC1, (e) CC2, (f) SS1, (g) SS2, and (h) SS3.

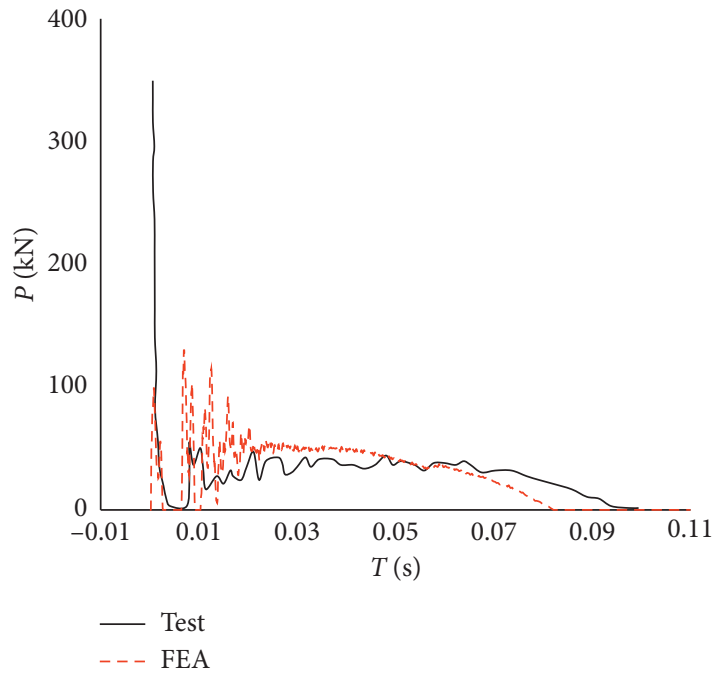

(a)

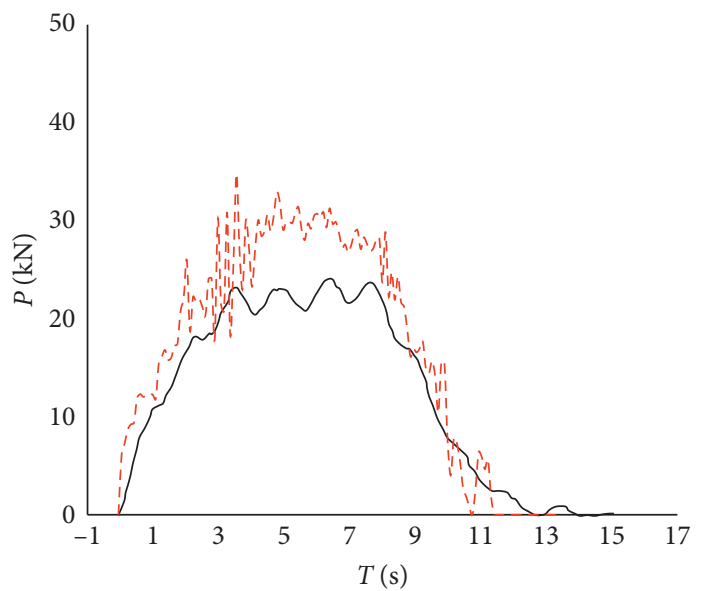

- Test

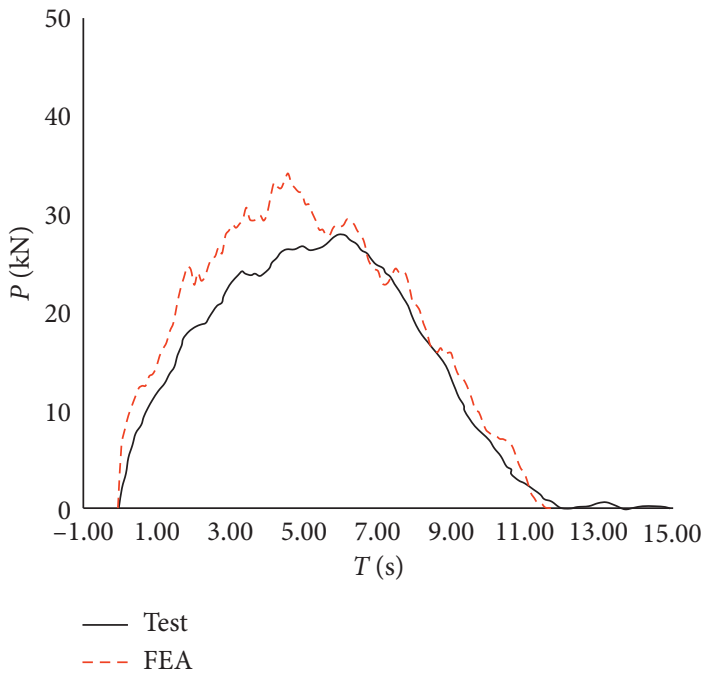

(b)

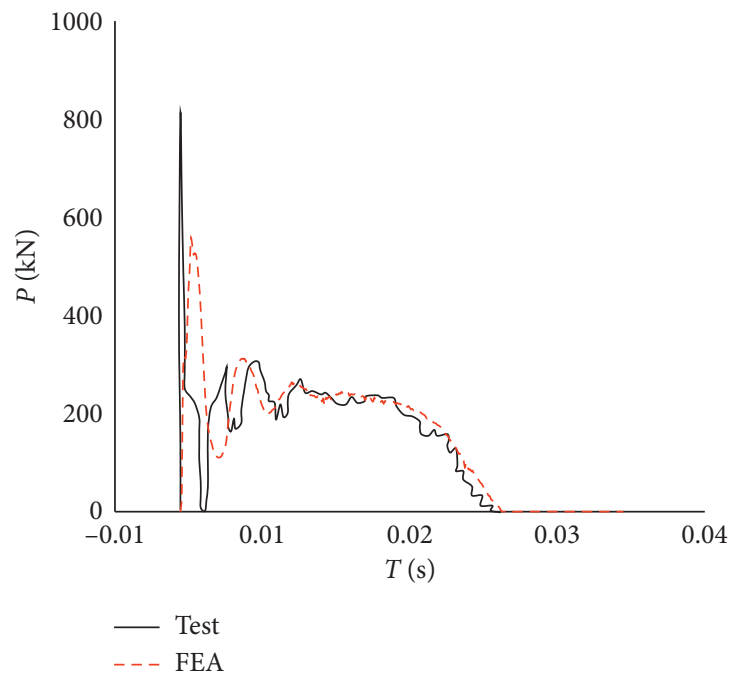

(d)

Figure 3: Continued. 


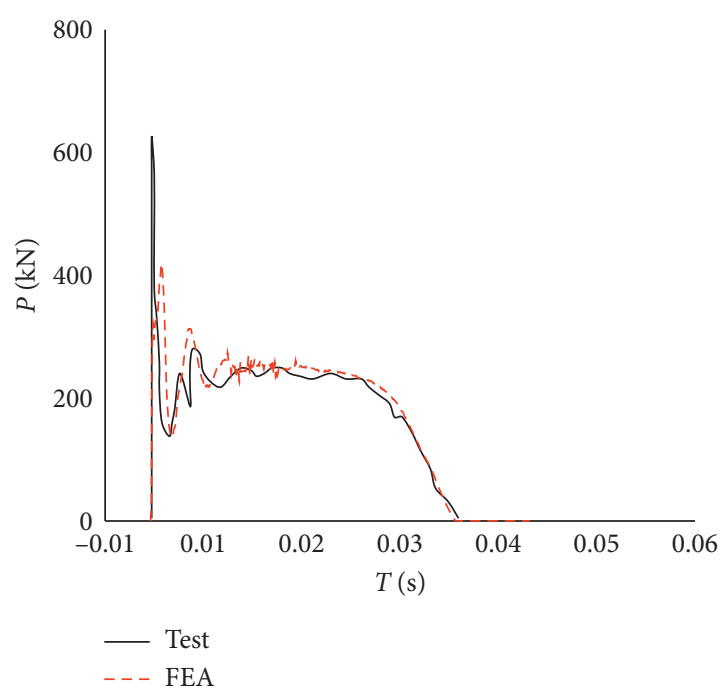

(e)

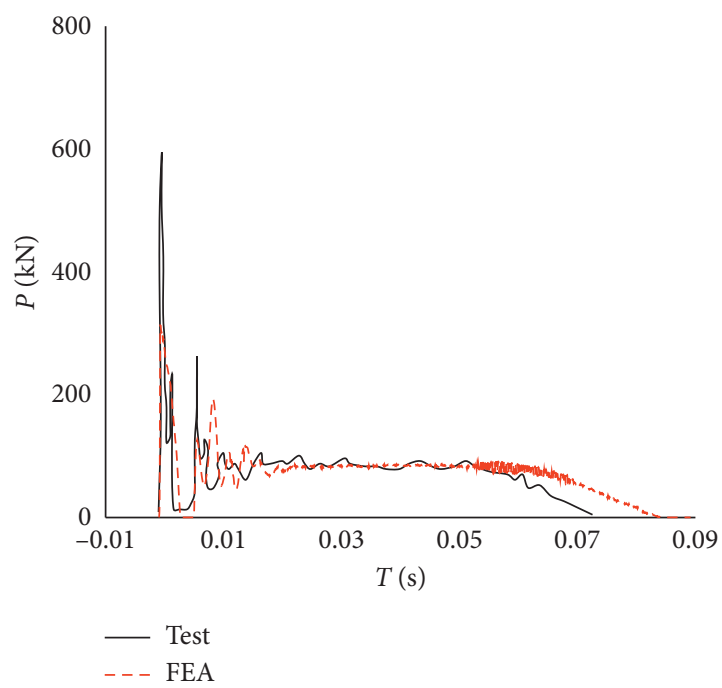

(g)

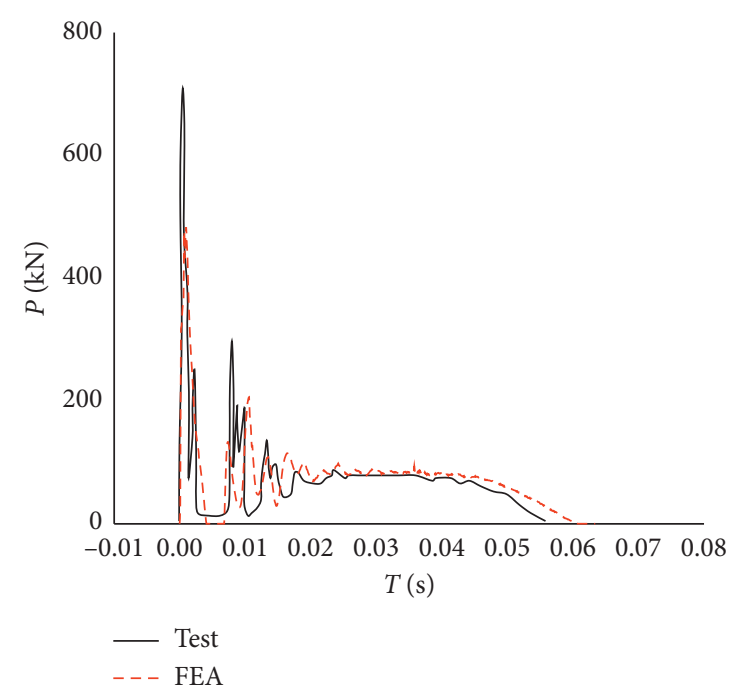

(f)

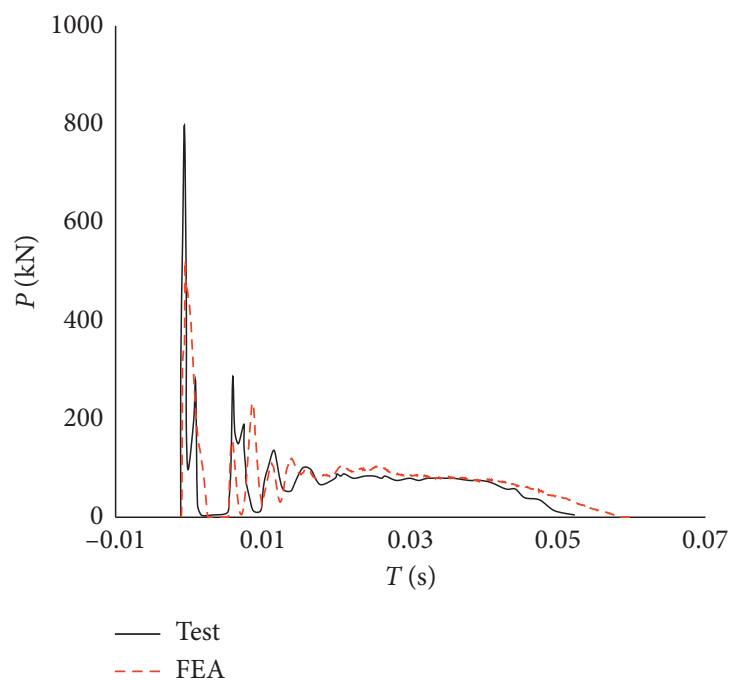

(h)

Figure 3: Impact force (P) versus time (T) curves. (a) MSH, (b) Pd1, (c) Pd2, (d) CC1, (e) CC2, (f) SS1, (g) SS2, and (h) SS3.

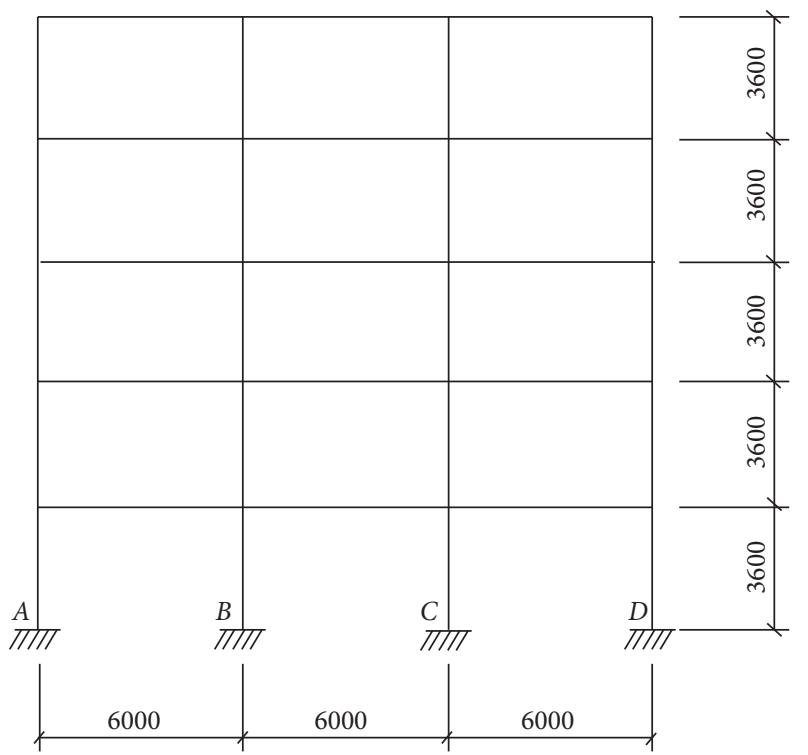

FIGURE 4: Elevation drawing of the plane frame (unit: $\mathrm{mm}$ ). 


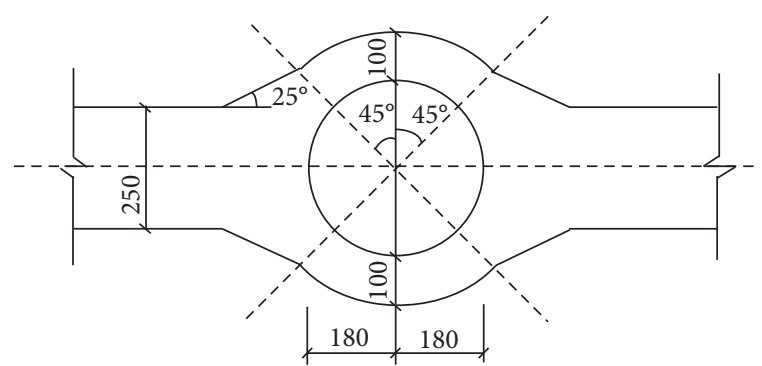

(a)

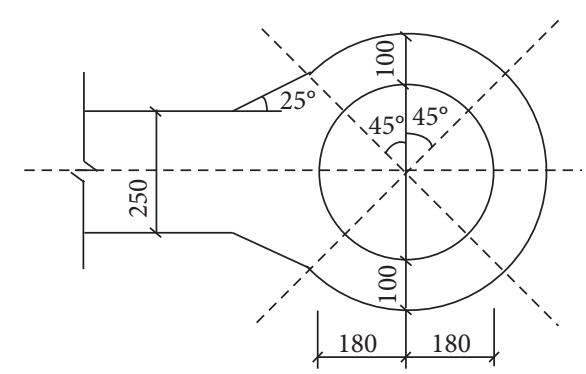

(b)

FIgURE 5: Joint construction (unit: mm). (a) Intermediate joint. (b) Exterior joint.

Loads: the vertical uniform load on all beams is $45 \mathrm{kN} /$ $\mathrm{m}$, and weight of the structure additionally is applied

\subsection{Method for Analysis of Progressive Collapse.} Considering the computational precision and cost, this paper presents a hybrid multiscale model including a beam element, shell element, and solid element. The couple function of interaction in ABAQUS is used to deal with the interface of different units and realize the connection between the fine model and the macroscopic model. The fine models of the impact column and the joint and the overall multiscale frame work for the direct simulation method (DS) and alternate path method (AP) are shown in Figure 6.

3.2.1. Direct Simulation Method (DS). The AP method does not need to consider the cause of column failure. Compared with the AP method, the impact condition which causes component failure is taken into account. There are many forms of accidental impact loads on building structures. The DS model considers the accidental impact conditions of the car crashing into the bottom column of the parking lot and specifically studies the impact degree of structural damage caused by such impact on the residual structure's resistance to continuous collapse.

Vehicle impact is one of the accidental loads with high uncertainty in the United States, according to the gross vehicular weight rating (GVWR), i.e., light-duty, mediumduty, and heavy-duty trucks. As shown in Figure 7(a), a medium-duty truck (F800 truck) is selected as the reference truck. This category and specific truck type are selected because (1) light trucks usually do not cause column damage; (2) F800 trucks are close to the lower bound of the heavy truck category when fully loaded. In addition, the truck may be overloaded, and it may cover certain aspects of the heavy truck category [26]; and (3) studies have shown that an overloaded F800 truck has the same serious impact effect as a heavy truck. Among the publically available finite-element truck models, the F800 truck model has been widely used and validated by many scholars $[27,28]$.

Chen [29] established an equivalent frame to simulate the impact of F800 truck and column collisions, and verified the validity of the model by comparing their deformation and internal energy relationship. The F800 truck is the equivalent of a frame, which is divided into a chassis channel, engine, and cargo, as shown in Figure 7(b). Three major impact parameters were selected to reflect the uncertainty of vehicle impact, including impact load, velocity, and height of the impact point of the F800 truck. In order to facilitate the comparison of various factors, 5 values are taken for each parameter. A total of 125 trials would be carried out; furthermore, calculation will be large if all the research combinations of each parameter are fully considered. It is necessarily simulated through a combination of noncomprehensive parameters and selecting representative test points, by which the reasonable influence of parameters can be shown. Therefore, each parameter value of analysis is used from the orthogonal test method as seen in Table 2.

3.2.2. Alternate Path Method (AP). The AP method is suitable for the analysis of structural collapse under blast and impact loads, which is based on the assumption that the failure of one or several main vertical members of the structure can be used to calculate the residual structural response.

3.2.3. Collapse Criterion. In this paper, the nonlinear dynamic collapse analysis of CFST plane frame structure is studied, and the failure criterion of limiting rotation angle value 12 of the steel beam is used from the code GSA [4]. The collapse occurred when the vertical displacement of the failed node is greater than $1275 \mathrm{~mm}$ which is the limiting displacement value corresponding to this frame.

\subsection{Comparative Analysis}

3.3.1. Collapse Mechanism. From Figure 8, it can be seen that there are two deformation modes of the failure column under impact load. The one is the local deformation of columns as shown in Figures 8(a) and 9(a), and the other is large deformation when the columns feet are destroyed as shown during the impact process in Figures 8(b), 8(c), 9(b), and $9(\mathrm{c})$. In addition, in the impact contact sites and the opposite sides of the steel pipes, there is stress centralization and partial steel pipes appeared with fracture; the relative obvious local deformation also occurred in the joint zone, as shown in Figure 9(c).

It can be known from Figures 8(a) and 8(b) separately that if the impact energy is low in the DS method, there is 


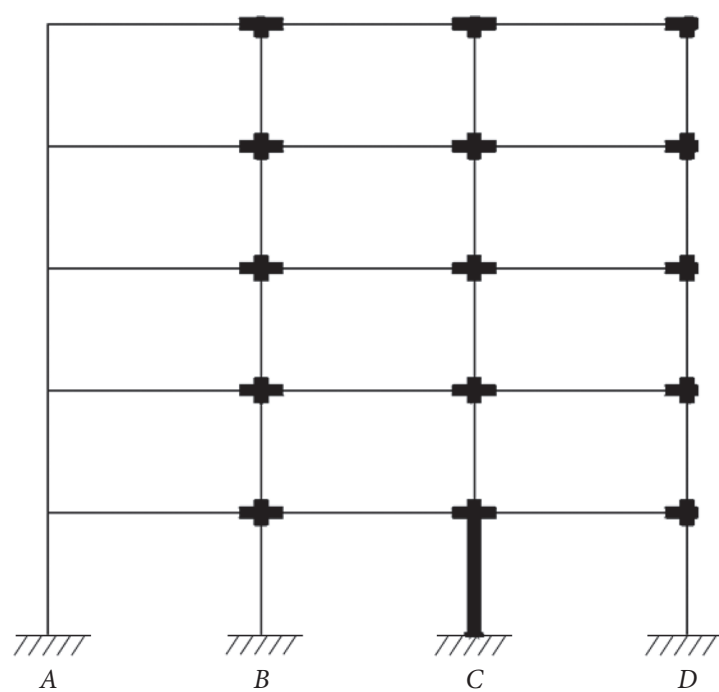

(a)

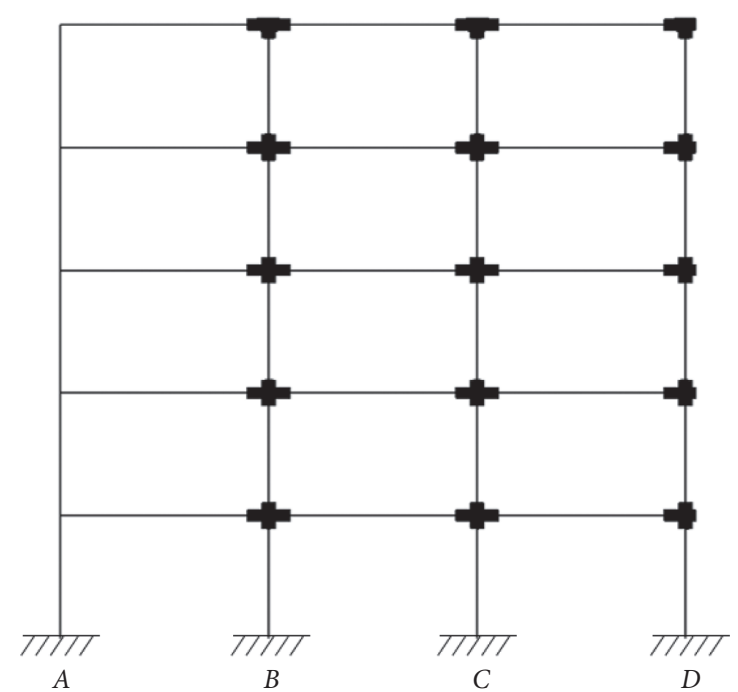

(b)

Figure 6: CFST plane frame structure model. (a) Model via the DS method. (b) Model via the AP method.

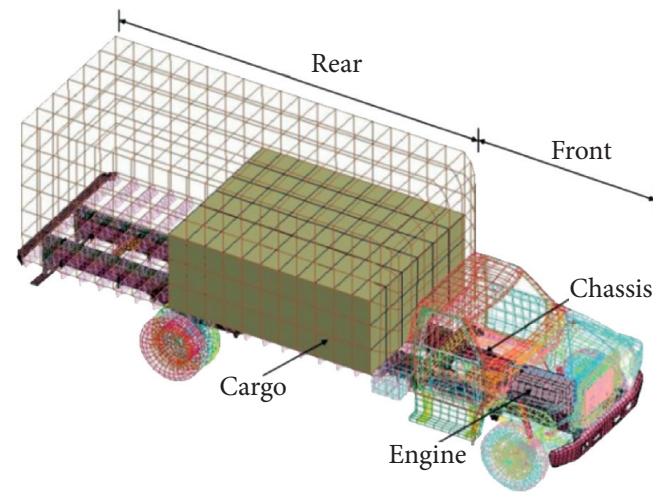

(a)

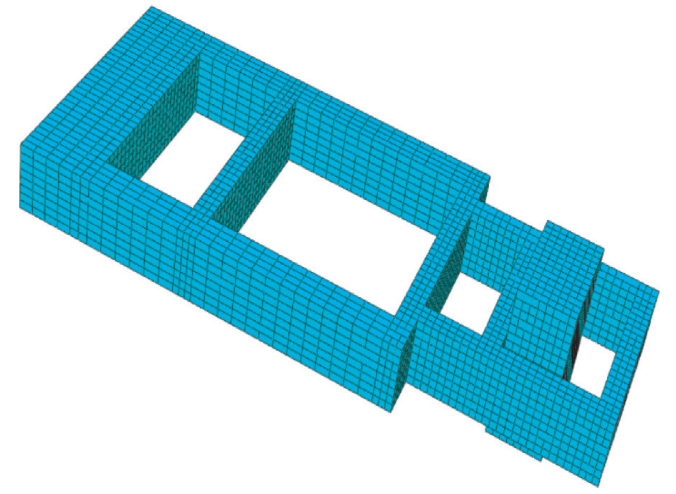

(b)

Figure 7: The car model. (a) 1995 Ford F800 truck. (b) Equivalent frame.

hardly any deformation in the remaining frame structure except for the small bending deformation of the impacted column; moreover, this column can still work. If the impacted column failed, the vertical displacement of beam ends and joints of this column is large, and there is scarcely any deformation in the remaining frame structure too. However, the internal force of the surplus structure is redistributed, and the integer collapse did not occur. As shown in Figure 8(c), the results of the AP method are similar to that of the DS method in Figure 8(b). After the destruction of the impacted column, the internal force is redistributed and a new equilibrium state of the frame finally appears due to the good deformation ability, ductility, and, furthermore, suspended cable effect of the steel beams.

3.3.2. Axial Force of Adjacent Columns. The axial-forcetime-history curves of the $A, B$, and $D$ bottom columns under different conditions are shown in Figures 10(a), $10(\mathrm{~b})$, and 10 (c). It can be seen that the forced state of the $B$ column is more unfavorable than that of the $A$ and $D$ columns. The change trends of axial force for $A, B$, and $D$ columns by the DS method are similar for each impact combination case. The axial force is significantly increased firstly as a result of the reverse vibration structure, and it decreases when time increases and then keeps a value in some level.

In the worst case, the maximum axial force of the $B$ column is 2.12 times of that of the AP method. More axial force is produced by the $B$ column as one of the adjacent columns because the impacted column is destroyed. In Figure 10, the result obtained by the AP method is generally close to the intermediate value of that of the DS method, and this only represents one of the impact combinations without practical significance. So, it is not reliable and, furthermore, insecure to evaluate the dynamic effect of the structure under the impact load by the AP method.

3.3.3. The Displacement of the Failure Point. As shown in Figure 11, the maximum displacement obtained by the AP method is $322 \mathrm{~mm}$ lower than $1275 \mathrm{~mm}$, which is the 
TABLE 2: Summary of research on transverse impact tests.

\begin{tabular}{|c|c|c|c|}
\hline No. & Impact velocity $(\mathrm{km} / \mathrm{h})$ & Impact mass $(t)$ & Impact position $(\mathrm{m})$ \\
\hline$c 1$ & 40 & 1.5 & 0.7 \\
\hline$c 2$ & 40 & 4.5 & 1.2 \\
\hline$c 3$ & 40 & 7.5 & 1.5 \\
\hline$c 4$ & 40 & 12 & 1.8 \\
\hline$c 5$ & 40 & 20 & 2.5 \\
\hline$c 6$ & 60 & 1.5 & 1.2 \\
\hline$c 7$ & 60 & 4.5 & 1.5 \\
\hline$c 8$ & 60 & 7.5 & 1.8 \\
\hline$c 9$ & 60 & 12 & 2.5 \\
\hline$c 10$ & 60 & 20 & 0.7 \\
\hline$c 11$ & 80 & 1.5 & 1.5 \\
\hline$c 12$ & 80 & 4.5 & 1.8 \\
\hline$c 13$ & 80 & 7.5 & 2.5 \\
\hline$c 14$ & 80 & 12 & 0.7 \\
\hline$c 15$ & 80 & 20 & 1.2 \\
\hline$c 16$ & 100 & 1.5 & 1.8 \\
\hline$c 17$ & 100 & 4.5 & 2.5 \\
\hline$c 18$ & 100 & 7.5 & 0.7 \\
\hline$c 19$ & 100 & 12 & 1.2 \\
\hline$c 20$ & 100 & 20 & 1.5 \\
\hline$c 21$ & 120 & 1.5 & 2.5 \\
\hline$c 22$ & 120 & 4.5 & 0.7 \\
\hline$c 23$ & 120 & 7.5 & 1.2 \\
\hline$c 24$ & 120 & 12 & 1.5 \\
\hline$c 25$ & 120 & 20 & 1.8 \\
\hline
\end{tabular}

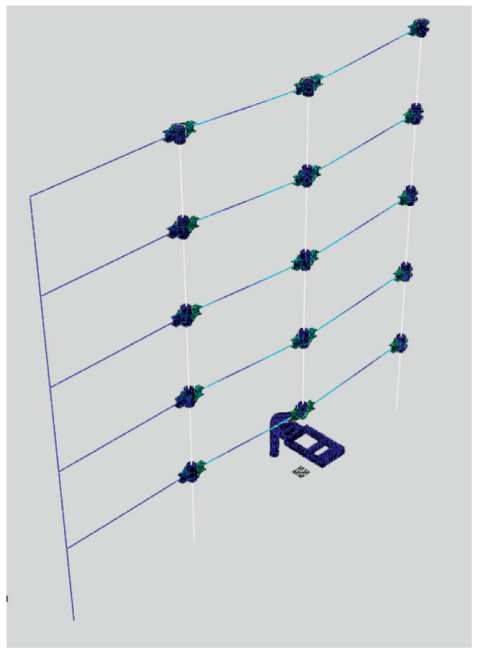

(a)

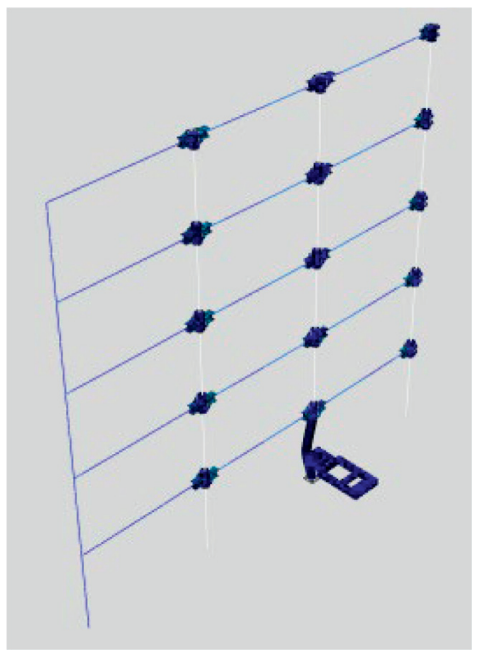

(b)

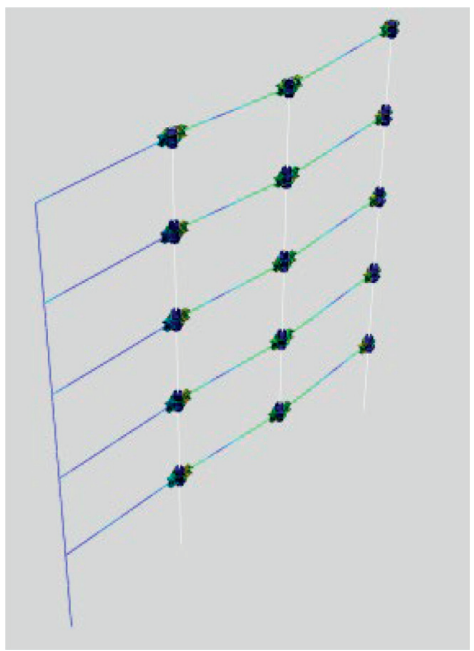

(c)

Figure 8: Deformation of the planer frame with the middle column removed. (a) Model c1 via the DS method. (b) Model c25 via the DS method. (c) Model via the AP method.

limiting displacement from the displacement-time-history curve of the failure point. It shows that the progressive collapse can be resisted by the five-layer plane frame structure. In the DS method, on the different impacted condition, the maximum value of the displacement variation is relatively larger, in the range of $17 \mathrm{~mm}-1274 \mathrm{~mm}$. However, compared with the AP method, the maximum displacement of the worst case in the DS method is $1274 \mathrm{~mm}$, basically reaching $1275 \mathrm{~mm}$, and the collapse may appear. It can be predicted that the DS method is more accurate than the AP method for analysis on collapse of frame structures.

3.3.4. Data Analysis. According to Figure 10, it can be concluded that the axial force of the B pillar changes most significantly after impacting. Therefore, in order to measure every impact factor on the frame impacted, the axial force 
S, Mises

Multiple section points (Avg: $75 \%$ )

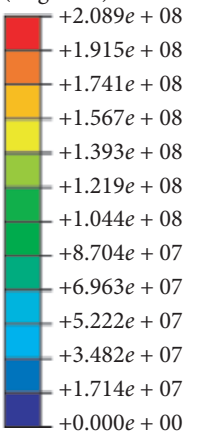

$+0.000 e+00$

Step: step-2

Increment 0 : step time $=0.0$

Primary var: S, Mises

Deformed var: $\mathrm{U}$ deformation scale factor: $+1.000 e+00$ Status var: STATUS

S, Mises

Multiple section points

(Avg: 75\%)

$+7.794 e+08$
$+7.145 e+08$
$+6.495 e+08$
$+5.846 e+08$
$+5.196 e+08$
$++4.547 e+08$
$++3.897 e+08$
$+3.248 e+08$
$++2.598 e+08$
$++1.949 e+08$
$+1.299 e+08$
$+6.497 e+07$
$+2.398 e+04$

$$
T=0.1047 \mathrm{~s}
$$

Step: step-2

Increment 142585: step time $=0.1047$

Primary var: S, Mises

Deformed var: $\mathrm{U}$ deformation scale factor: $+1.000 e+00$

Status var: STATUS
S, Mises

Multiple section points

(Avg: 75\%)

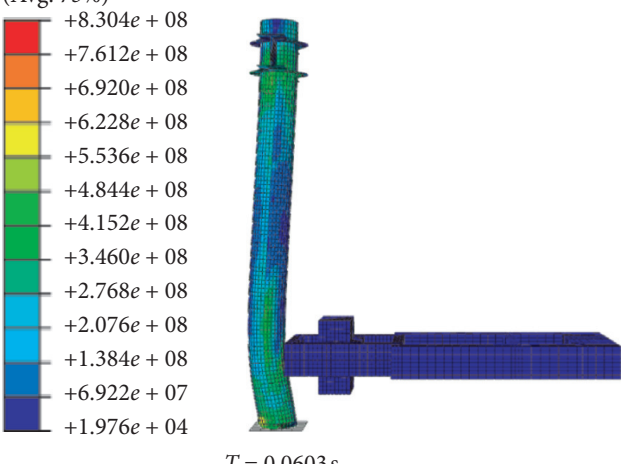

Step: step-2

Increment 81229: step time $=6.0300-02$

Primary var: $\mathrm{S}$, mises

Deformed var: $\mathrm{U}$ deformation scale factor: $+1.000 e+00$

Status var: STATUS

S, Mises

Multiple section points

(Avg: 75\%)
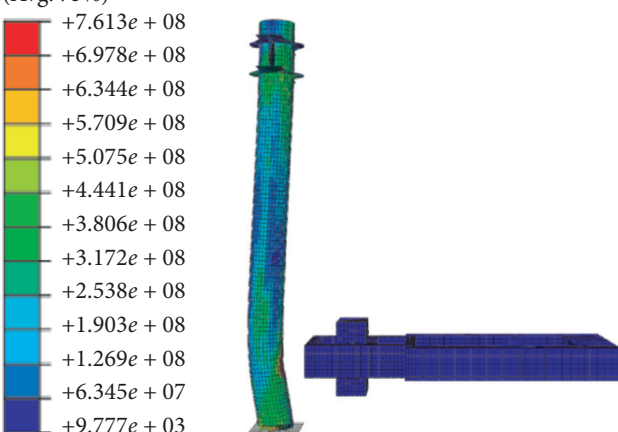

$T=0.15 \mathrm{~s}$

Step: step-2

Increment 204871: step time $=0.1500$

Primary var: S, Mises

Deformed var: $\mathrm{U}$ deformation scale factor: $+1.000 e+00$ Status var: STATUS

(a)

FIgURE 9: Continued. 

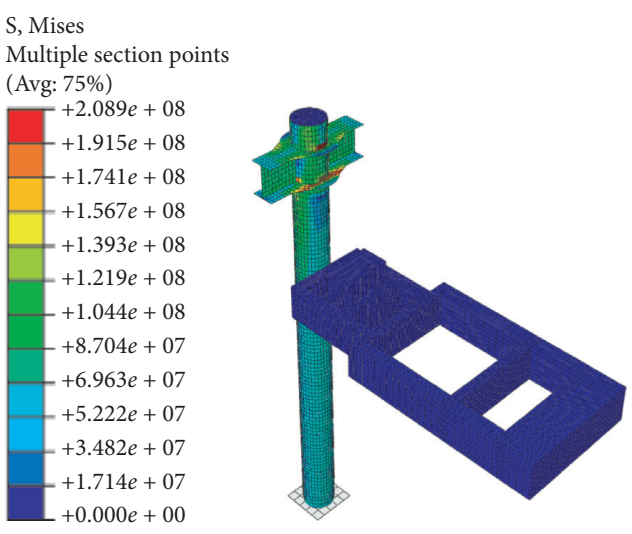

$T=0.0 \mathrm{~s}$

Step: step-2

Increment 0 : step time $=0.0$

Primary var: S, Mises

Deformed var: U deformation scale factor: $+1.000 e+00$

Status var: STATUS

S, Mises

Multiple section points

(Avg: $75 \%$ )

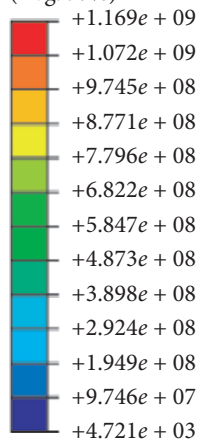

$+4.721 e+03$

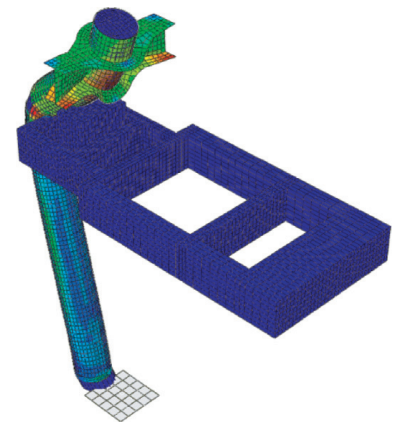

$T=0.1023 \mathrm{~s}$

Step: step-2

Increment 137769: step time $=0.1023$

Primary var: S, Mises

Deformed var: $\mathrm{U}$ deformation scale factor: $+1.000 e+00$

Status var: STATUS

S, Mises

Multiple section points

(Avg: 75\%)
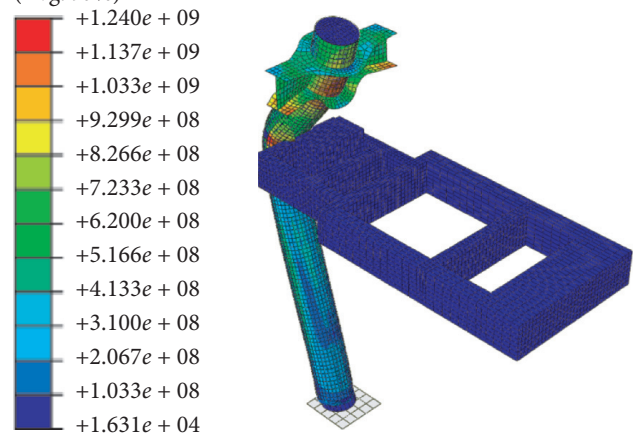

$T=0.0603 \mathrm{~s}$

Step: step-2

Increment 79654: step time $=6.0301 E-02$

Primary var: S, Mises

Deformed var: $\mathrm{U}$ deformation scale factor: $+1.000 e+00$

Status var: STATUS

S, Mises

Multiple section points

(Avg: 75\%)
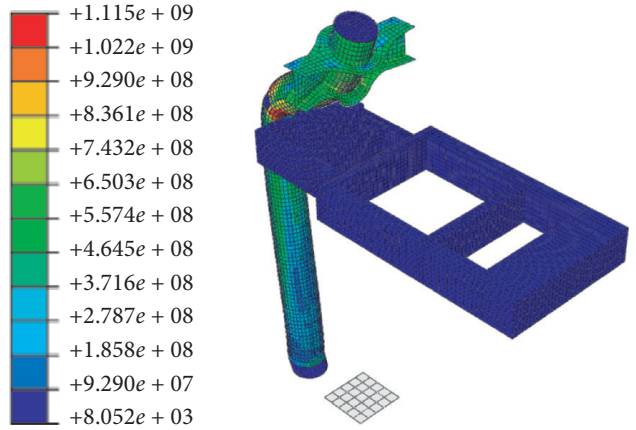

$T=0.147 \mathrm{~s}$

Step: step-2

Increment 200775: step time $=0.1476$

Primary var: $\mathrm{S}$, Mises

Deformed var: $\mathrm{U}$ deformation scale factor: $+1.000 e+00$

Status var: STATUS

(b)

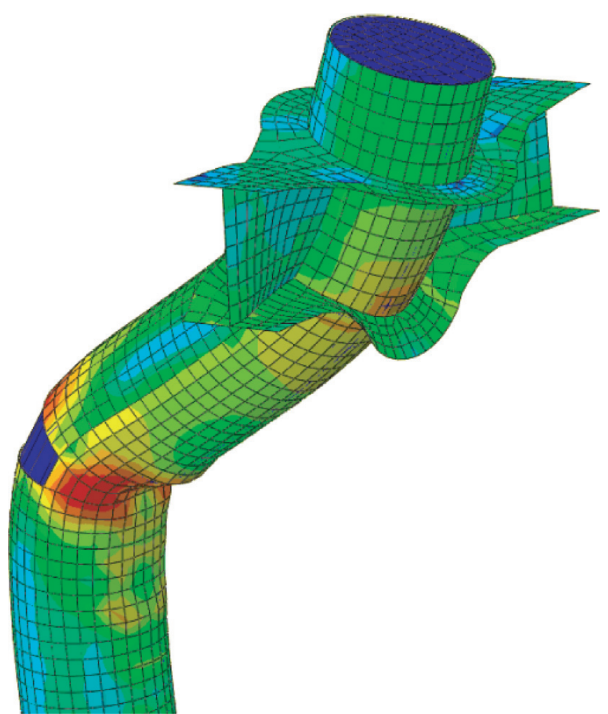

(c)

FIgURE 9: The collapse process by the DS method. (a) Local deformation of column failure. (b) Large deformation of column failure. (c) Failure deformation of the column and joint. 

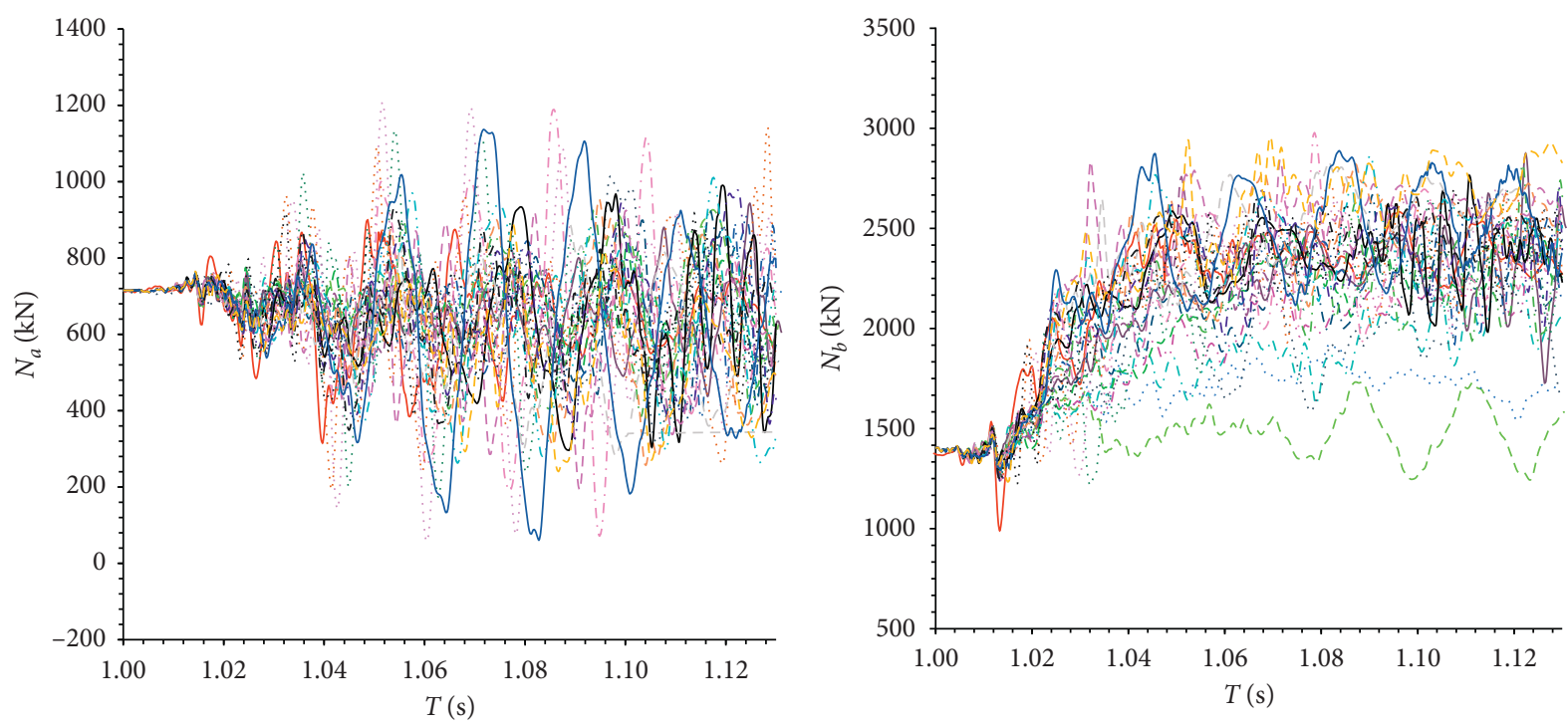

\begin{tabular}{|c|c|c|c|}
\hline AP & $\cdots C 7$ & $\mathrm{C} 14$ & $\cdots C 20$ \\
\hline$---C 1$ & $-C 8$ & $--C 15$ & $---C 21$ \\
\hline$C 2$ & $---C 9$ & $-C 16$ & C22 \\
\hline C3 & … C10 & $---C 17$ & $--C 23$ \\
\hline$C 4$ & $\cdot-\cdot-C 11$ & ..... C18 & $-C 24$ \\
\hline C5 & $\mathrm{C} 12$ & $-\cdot C 19$ & $---C 25$ \\
\hline C6 & $-C 13$ & & \\
\hline
\end{tabular}

(a)

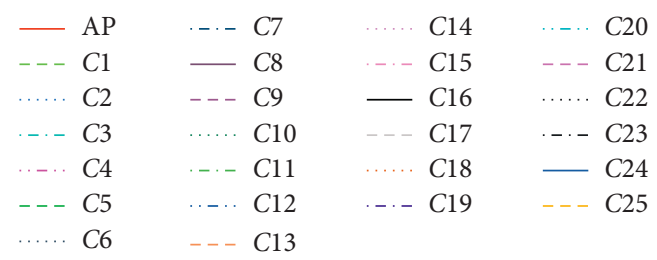

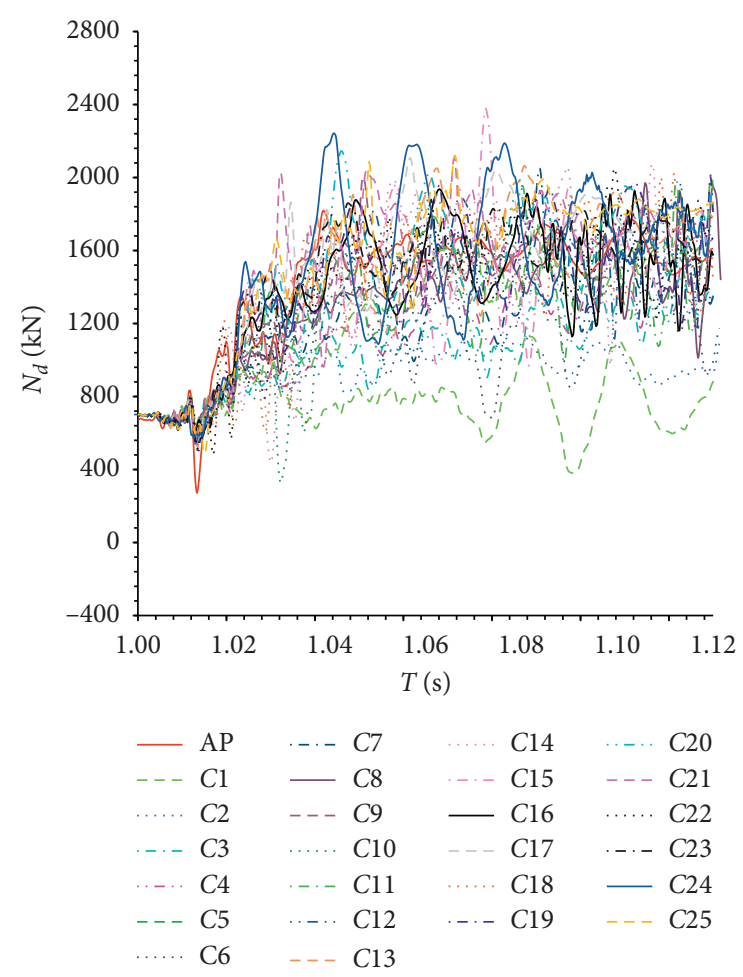

(c)

Figure 10: Internal force versus time (T) curves. (a) Axial force of the A bottom column. (b) Axial force of the B bottom column. (c) Axial force of the D bottom column. 


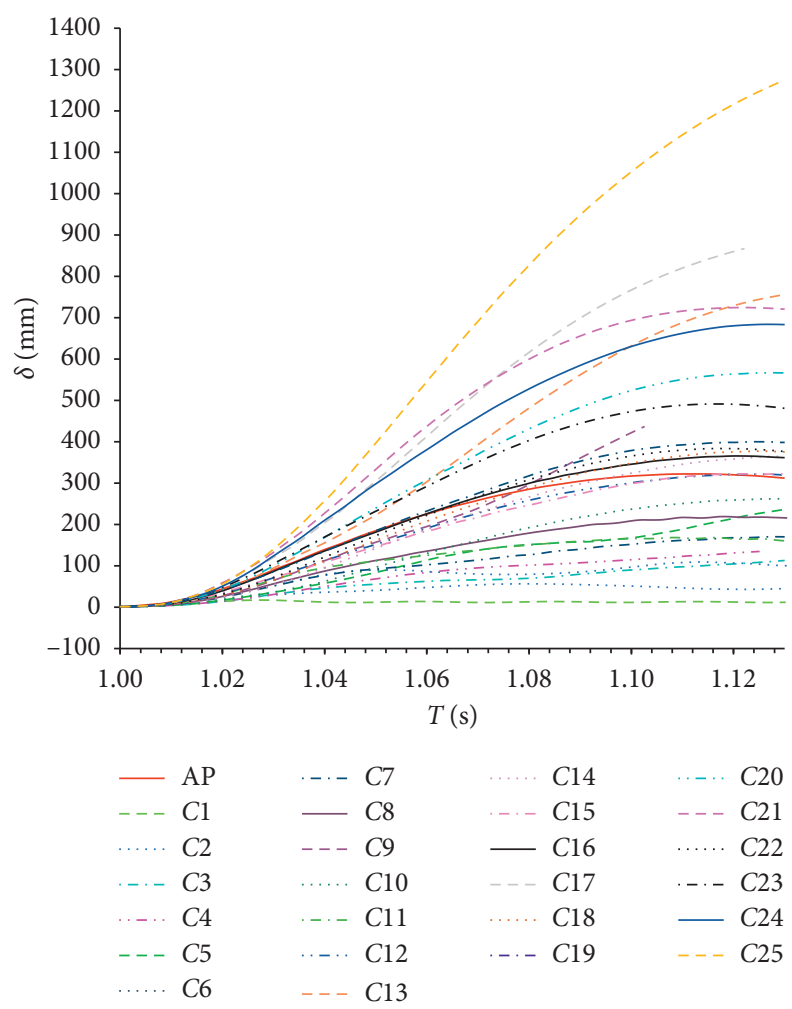

FIGURE 11: Vertical displacement of the failure column node versus time $(T)$ curves.

TABLE 3: Summary of data analysis on transverse impact tests.

\begin{tabular}{|c|c|c|c|c|}
\hline No. & Impact velocity $(\mathrm{km} / \mathrm{h})$ & Impact mass $(\mathrm{t})$ & Impact position $(\mathrm{m})$ & $\eta$ \\
\hline$c 1$ & 40 & 1.5 & 0.7 & 1.23 \\
\hline$c 2$ & 40 & 4.5 & 1.2 & 1.37 \\
\hline$c 3$ & 40 & 7.5 & 1.5 & 1.62 \\
\hline$c 4$ & 40 & 12 & 1.8 & 1.73 \\
\hline$c 5$ & 40 & 20 & 2.5 & 1.80 \\
\hline$c 6$ & 60 & 1.5 & 1.2 & 1.74 \\
\hline$c 7$ & 60 & 4.5 & 1.5 & 1.90 \\
\hline$c 8$ & 60 & 7.5 & 1.8 & 2.05 \\
\hline$c 9$ & 60 & 12 & 2.5 & 1.96 \\
\hline$c 10$ & 60 & 20 & 0.7 & 1.92 \\
\hline$c 11$ & 80 & 1.5 & 1.5 & 2.01 \\
\hline$c 12$ & 80 & 4.5 & 1.8 & 1.89 \\
\hline$c 13$ & 80 & 7.5 & 2.5 & 2.01 \\
\hline$c 14$ & 80 & 12 & 0.7 & 1.93 \\
\hline$c 15$ & 80 & 20 & 1.2 & 2.12 \\
\hline$c 16$ & 100 & 1.5 & 1.8 & 1.97 \\
\hline$c 17$ & 100 & 4.5 & 2.5 & 2.02 \\
\hline$c 18$ & 100 & 7.5 & 0.7 & 1.94 \\
\hline$c 19$ & 100 & 12 & 1.2 & 1.93 \\
\hline$c 20$ & 100 & 20 & 1.5 & 2.04 \\
\hline$c 21$ & 120 & 1.5 & 2.5 & 2.02 \\
\hline$c 22$ & 120 & 4.5 & 0.7 & 1.92 \\
\hline$c 23$ & 120 & 7.5 & 1.2 & 1.89 \\
\hline$c 24$ & 120 & 12 & 1.5 & 2.06 \\
\hline$c 25$ & 120 & 20 & 1.8 & 2.11 \\
\hline$k_{1}$ & 1.550 & 1.794 & 1.788 & - \\
\hline$k_{2}$ & 1.914 & 1.820 & 1.810 & - \\
\hline$k_{3}$ & 1.992 & 1.902 & 1.926 & - \\
\hline$k_{4}$ & 1.980 & 1.922 & 1.950 & - \\
\hline$k_{5}$ & 2.000 & 1.998 & 1.962 & - \\
\hline$R$ & 0.45 & 0.204 & 0.174 & \\
\hline
\end{tabular}




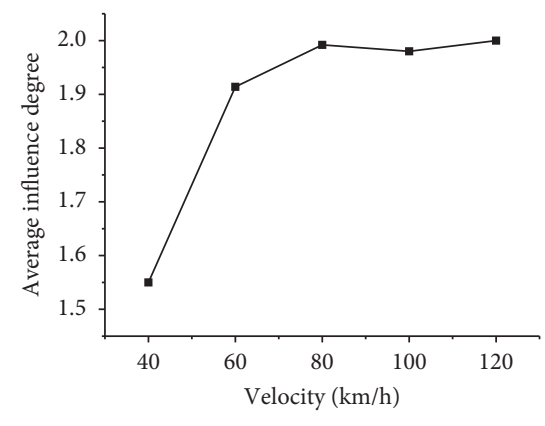

(a)

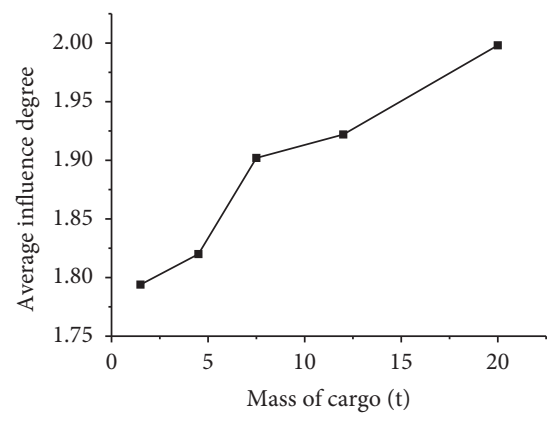

(b)

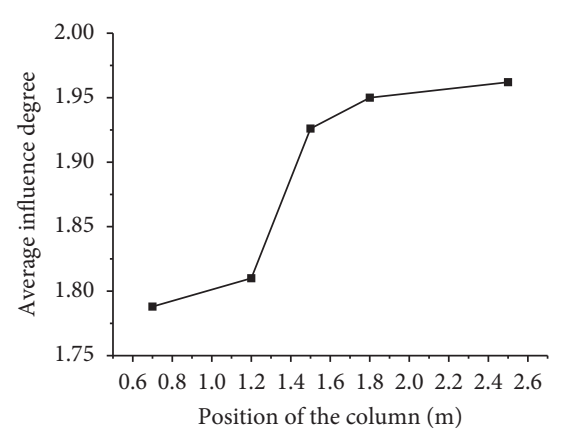

(c)

Figure 12: Single-factor analysis. (a) Velocity influence. (b) Massin fluence. (c) Position influence.

variation parameter $\eta$ for the B pillar was introduced as the ratio of the postimpact axial force to that of preimpact in Table 3. By the principle of orthogonal design, the sum of the parameters $\eta$ in the velocity (or mass and position) factor at the $i$ level is given by $K_{i}$,

$$
K_{i}=\sum_{j=1}^{n} \eta_{j i},
$$

where $\eta_{j i}$-the ratio value of velocity (or mass and position) factor for the $j$ th test of frame at the $i$ th level; $n$-the number of occurrences of each level in 25 tests, $n=25 / 5=5,1 \leq i \leq 5$, $1 \leq j \leq 5$.

The average value of velocity (or mass and position) factor at each level is obtained by $k_{i}$, whose formula is shown in Table 3:

$$
k_{i}=\frac{K_{i}}{n(i=1,2,3,4,5)} .
$$

For every factor (velocity, mass, or position), the parameter $R$ value is the largest one of these five numbers minus the smallest one, which reflected the change with the level fluctuation of this factor. The $R$ value is larger, and the influence factor is more important. According to the value of $R$, the order of the importance of the factors can be determined, and it can be seen that the most obvious factor is the velocity, as shown in Table 3 .

$$
R=\max \left(k_{i}\right)-\min \left(k_{j}\right)(i, j=1,2,3,4,5) .
$$

The single-factor analysis is also shown in Figure 12, from which the following conclusions can be drawn: velocity in the range of $40-80 \mathrm{~km} / \mathrm{h}$, and the average influence degree increased significantly with the increase of velocity value, more than $80 \mathrm{~km} / \mathrm{h}$ less affected in Figure 12(a). As shown in Figure 12(b), the effect of mass on the average influence degree is close to linear growth. It can be concluded from Figure 12(c) that the average influence degree increased with the increase of the distance of the impact point from the bottom of the column.

\section{Conclusions}

The application of two methods including the AP method and the DS method is discussed in this paper, which is studied on resisting the progressive collapse of the concretefilled steel tubular (CFST) frame structure under lowvelocity impact load. The conclusions and recommendations from this study can be summarized as follows:

(1) It is presented that the most obvious factor is the velocity for every factor (velocity, mass, or position) on impact effect.

(2) From the collapse criterion, no frame-progressive collapse occurred via the AP method; however, the vertical collapse nearly occurred by the DS method. Due to the failure of the C column in a moment by the AP method, the internal force of the remaining structure is redistributed. The loading which was once carried by the $\mathrm{C}$ column is transferred to the adjacent columns, and finally, a new equilibrium state of the structure is reached. It can be seen that the resisting collapse capacity of the CFST frame under impact loading cannot be accurately estimated by this method because the specific cause of component failure is not considered and the analysis is oversimplified.

(3) In the DS method, the C column failed in a very short time due to the rapid violent impact of the car. At the same time, some dynamic response and degree of damage are produced on the members adjacent to the $\mathrm{C}$ column immediately, resulting in a large vertical displacement, and the collapse may appear. The result by the DS method is closer to the actual condition, and the collapse process of the structure under impact load can be accurately described.

\section{Data Availability}

The data used to support the findings of this study are included within the article.

\section{Conflicts of Interest}

The authors declare no conflicts of interest.

\section{Acknowledgments}

This research was financially supported by the Natural Science Foundation of Chongqing (No. cstc2019jcyj- 
msxmX0440), the Science and Technology Research Program of the Chongqing Municipal Education Commission (Grant No. KJQN201901339), and the science and technology project of Chongqing University of Arts and Sciences (Nos. 2017RJJ31 and P2018JG13).

\section{References}

[1] C. Pearson and N. Delatte, "Lessons from the progressive collapse of the ronan point apartment tower," Third Forensic Engineering Congress, pp. 190-200, 2003.

[2] J. D. Osteraas, "Murrah Building Bombing Revisited: a qualitative assessment of blast damage and collapse patterns," Journal of Performance of Constructed Facilities, vol. 20, no. 4, pp. 330-335, 2006.

[3] Z. P. Bažant, J. L. Le, F. R. Greening et al., "What did and did not cause collapse of world trade center twin towers in New York?" Journal of Engineering Mechanics, vol. 134, no. 10, pp. 892-906, 2008.

[4] GSA, Progressive Collapse Analysis and Design Guidelines for New Federal Office Buildings and Major Modernization Projects, US General Services, New York, NY, USA, 2013.

[5] Eurocode1-Actions on Structures, Part1-7: General ActionsAccidental Actions. EN1991-1-7. 2005.

[6] Japanese Society of Steel Construction Council on Tall Buildings, "Guidelines for collapse control design, I Design," Journal of Womens Health, 2005.

[7] Japanese Society of Steel Construction Council on Tall Buildings and Urban, "Guidelines for collapse control design, II Research," Journal of Womens Health, 2005.

[8] DoD, "Design of structures to resist progressive collapse," US Department of Defense (DoD), New York, NY, USA, 2009.

[9] Chinese standard CECS28, Technical Specification for Concrete-Filled Steel Tubular Structures, Chinese Standard, Beijing, China, 2012.

[10] M. M. Kou, Y. J. Lian, and Y. T. Wang, "Numerical investigations on crack propagation and crack branching in brittle solids under dynamic loading using bond-particle model," Engineering Fracture Mechanics, vol. 212, pp. 41-56, 2019.

[11] M. Kou, J. Bi, B. Yuan, and Y. Wang, "Peridynamic analysis of dynamic fracture behaviors in FGMs with different gradient directions," Structural Engineering and Mechanics, vol. 75, no. 3, pp. 339-356, 2020.

[12] S. Gerasimidis and J. Sideri, "A new partial-distributed damage method for progressive collapse analysis of steel frames," Journal of Constructional Steel Research, vol. 119, pp. 233-245, 2016.

[13] Y. Al-Salloum, T. Almusallam, T. Ngo et al., "Progressive collapse analysis of a medium-rise circular RC building against blast loads," Asme International Conference on Ocean, 2016.

[14] Y. Ding, X. Song, and H.-T. Zhu, "Probabilistic progressive collapse analysis of steel frame structures against blast loads," Engineering Structures, vol. 147, pp. 679-691, 2017.

[15] J. Jiang and G.-Q. Li, "Disproportionate collapse of 3D steelframed structures exposed to various compartment fires," Journal of Constructional Steel Research, vol. 138, pp. 594-607, 2017.

[16] L. Shan, F. Petrone, and S. Kunnath, "Robustness of RC buildings to progressive collapse: influence of building height," Engineering Structures, vol. 183, pp. 690-701, 2019.

[17] J. Wang, B. Uy, D. Li et al., "Progressive collapse analysis of stainless steel composite frames with beam-to-column endplate connections," Steel and Composite Structures, vol. 36, no. 4, pp. 427-446, 2020.

[18] D.-Y. Kong, B. Yang, M. Elchalakani, K. Chen, and L.-M. Ren, "Progressive collapse resistance of 3D composite floor system subjected to internal column removal: experiment and numerical simulation," Journal of Constructional Steel Research, vol. 172, p. 106208, 2020.

[19] M. El-Desoqi, M. Ehab, and H. Salem, "Progressive collapse assessment of precast reinforced concrete beams using applied element method," Case Studies in Construction Materials, vol. 13, 2020.

[20] Y. Zhou, T. Chen, Y. Pei et al., "Static load test on progressive collapse resistance of fully assembled precast concrete frame structure," Engineering Structures, vol. 200, Article ID 109719, 2019.

[21] J. X. Zhang, G. Shi, Y. Q. Wang et al., "Research on progressive collapse of steel frames," Steel Construction, pp. 51-69, 2012.

[22] M. Yousuf, B. Uy, Z. Tao, A. Remennikov, and J. Y. R. Liew, "Impact behaviour of pre-compressed hollow and concrete filled mild and stainless steel columns," Journal of Constructional Steel Research, vol. 96, pp. 54-68, 2014.

[23] M. Zeinoddini, G. A. R. Parke, and J. E. Harding, "Axially preloaded steel tubes subjected to lateral impacts: an experimental study," International Journal of Impact Engineering, vol. 27, no. 6, pp. 669-690, 2002.

[24] L.-H. Han, C.-C. Hou, X.-L. Zhao, and K. J. R. Rasmussen, "Behaviour of high-strength concrete filled steel tubes under transverse impact loading," Journal of Constructional Steel Research, vol. 92, pp. 25-39, 2014.

[25] P. S. Symonds, "Survey of methods of analysis for plastic deformation of structures under dynamic loading," Ciência E Tecnologia De Alimentos, vol. 31, pp. 967-972, 1967.

[26] L. Chen, S. El-Tawil, and Y. Xiao, "Reduced models for simulating collisions between trucks and bridge piers," Journal of Bridge Engineering, vol. 21, no. 6, Article ID 04016020, 2016.

[27] S. El-Tawil, E. Severino, and P. Fonseca, "Vehicle collision with bridge piers," Journal of Bridge Engineering, vol. 10, no. 3, pp. 345-353, 2005.

[28] H. Dawson and D. Tennant, "Inelastic dynamic finite-element design of bollard systems to impact loading," Structures Congress, 2014.

[29] L. Chen, Y. Xiao, and S. El-Tawil, "Impact tests of model RC columns by an equivalent truck frame," Journal of Structural Engineering, vol. 142, no. 5, Article ID 04016002, 2016. 